\title{
Automatic Watering Potted Microcontroller-based System
}

\author{
Dan Chen \\ School of North China Electric Power University, Baoding 071000, China; \\ 1241341732@qq.com
}

Keywords: Microcontroller, Automatic watering

\begin{abstract}
Nowadays, more and more people are tending to place several plants to beautify their living environment. But the following problems show that it's not easy to raising green plants. For example, people always forget the lovely lives because of the fast-paced life, so the plants will dead. But some people are accustomed to watering too much so that plants become putrid. In addition, as for the plants-shop owners, a variety of green plants on weekdays conservation is very heavy workload. To solve these problems, we developed a set of automatic watering systems.
\end{abstract}

\section{Introduction}

The system is divided into three parts: detection, control part, operative. The detection part mainly means soil moisture sensor, which is to monitor soil moisture, and pass the information on to the next section. Control part is microcontrollers, which will analyze the signal from the soil humidity sensor and transform it into signal that can be recognized by the electromagnetic valve. Operative is the solenoid valve, works differently on different signals from the SCM response, namely control the closure of the switch, at the same time, the operative part need to send the result signal to the control part [1].

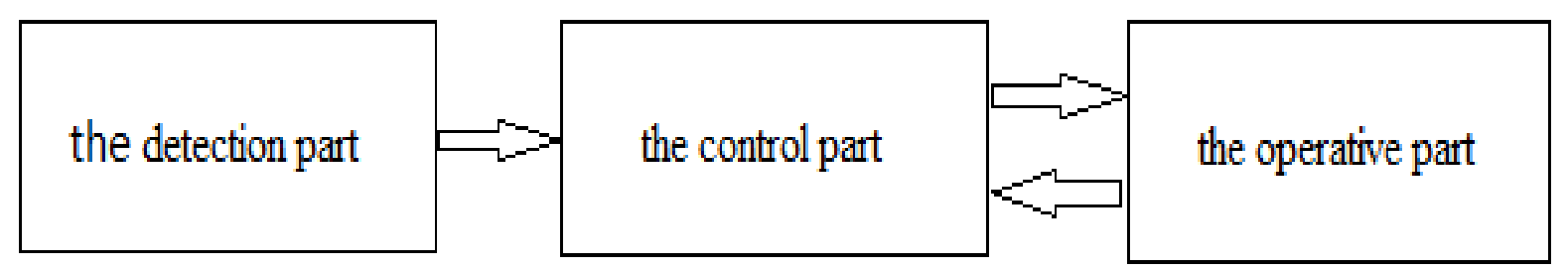

Fig. 1 The Structure diagram of Automatic watering potted microcontroller-based system

\section{Background}

As we all know, plants can absorb the computer radiation, generate fresh air, and create a bright and warm atmosphere of life. Meanwhile, plants can make people feel happy. As a result, people are increasingly inclined to place potted plants on the desk to make their boring work more brighten. However, a number of issues attendant brings us quite a headache:

1. Some delicate plants is very demanding to environment. It is difficult to control water supply when watering. The plants will dry up if we watering too little, conversely, plants will rot if watering too much. Therefore, we should provide suitable water to plants.

2. With the improvement of people's living standard, more and more people at home have a potted plant, However, with the fast pace of life, the big life pressure, the busy work, people often forget to water the plants. It is easy to cause the flowers wither and die; College students and white-collar workers like some green plant and put it in the state, during the holiday the plant will die because of long time without water 
3. When the seller watering plants, they should remember the database for every plant. It is a big job. And plants are probable to dead without suitable care.

\section{Biological knowledge}

To solve these problems, we have developed the automatic watering potted microcontroller-based system. This system is designed for the persons who have no time or experience to take care of the plants. and it can automatically detect the main idea of complete automatic watering plants watering work.

Water is an important part of the plants; it weighs 75\% 90\% of fresh plants. Plants absorb from the soil and transport of inorganic salts and organic compounds in the body, such as photosynthesis, respiration, transpiration. The process can't take place without water participation. The material conditions of water are essential for plant survival, also affect plant morphology, growth, important physiological factors such as reproduction and seed dispersal. Thus, water can directly affect the health of plant growth. Too much water will make the roots of the plant rot and it can inhibit flower bud differentiation so the plants will death; Too little water will cause the plants to die.

Plants rely mostly on root hairs to absorb water from the soil, then spread to various organs of the body, for the growth and development. The requirement for the different plants are not the same. The requirements of water for plants with large leaves, soft texture, smooth hairless is large; On the contrary, plants with leaf surface of the small, hard or waxy layer or dense hair need less water. The water requirement for different plants is not the same during different growth period. Dormancy and germination required less water, lush shoots water requirements. During flower bud differentiation of water, and often used "hold water" measures to promote the flower bud formation in flowering[2].

Moisture index is a reflection of potted plants an important indicator of moisture condition on the growth and development of plants, soil moisture representation. Generally divided into dry, suitable, over three levels, most potted plants suitable indicators for soil moisture relative humidity $60 \% \sim 80 \%$. Water deficit surplus very significant effect on plant growth, according to the extent of the amount of water affect the growth of the high starting point of plant drought and waterlogging of the indicators.

From the direction of domestic and foreign research status and potted plants moisture measurement and control system, the main potted plant moisture measurement and control system is based on microcontroller and PC control can be based on real-time watering soil moisture automatic control system based on capillary irrigation capillary pipe expansion irrigation system. Automatic watering potted microcontroller-based system with high precision, small size, low price, etc., is the ideal research. Based on soil moisture sensor information collection system, single-chip data processing systems and the implementation of systems based on electromagnetic relay action is based on the main part of potted automatic watering system.

\section{Project details}

Soil moisture sensor based on the core information collection system is the soil moisture sensor. Mainly used to measure the volumetric soil water content, soil moisture sensor is to monitor soil moisture, its hardware control circuit buried in the soil moisture sensors to monitor soil moisture in the root of the root crop, the sensor circuit will be tested "high humidity" and "humidity too low" signal transmitted by the encoder master controller, the master controller determines the control state. "High humidity" stop irrigation; "humidity too low" through the optical isolation, relay control in the water solenoid valve. The system also has a fault alarm. The main controller through the communication interface with the host computer communication, real-time monitoring of system health or the historical data analysis [3]. 


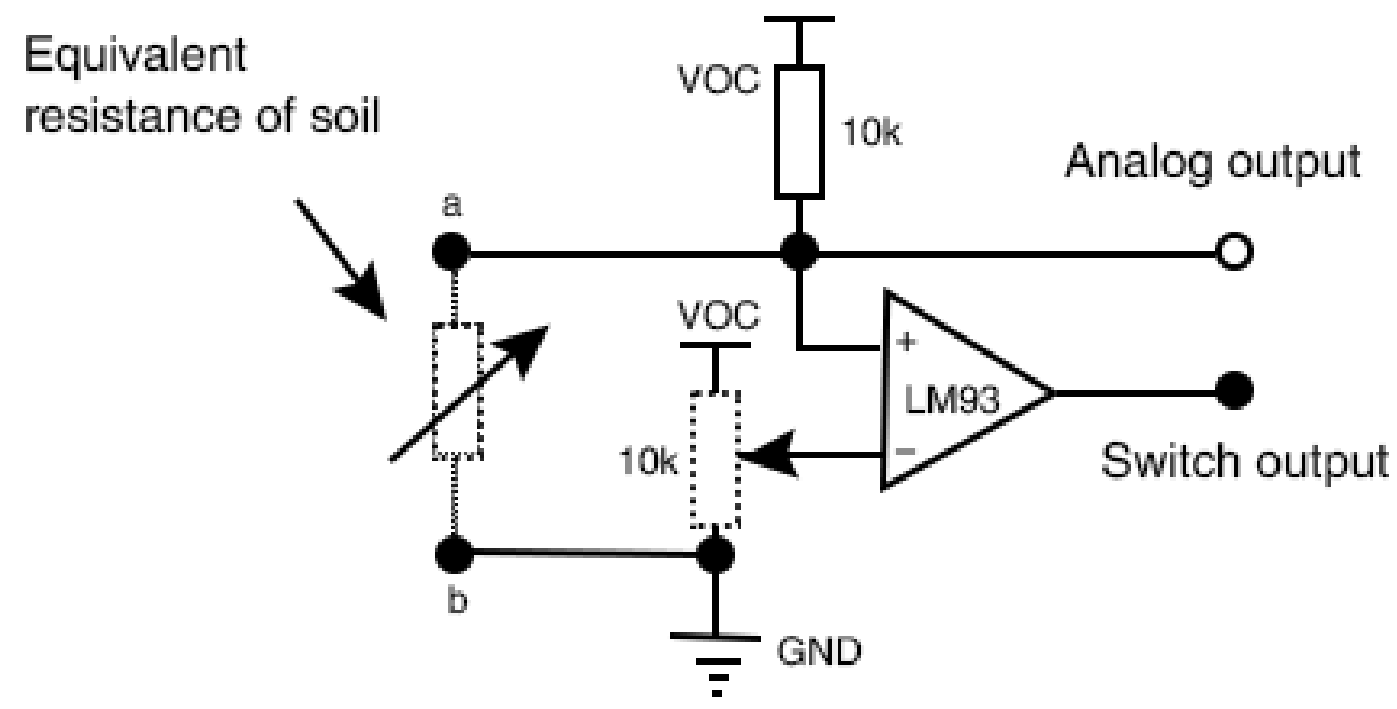

Fig. 2 The principle diagram of the soil moisture sensor

Microcontroller-based data processing system is the core of the whole system, from the microcontroller to accept soil moisture sensor based on the incoming data and with the water demand already set the type of plants were compared and judged whether the plant water, if the water shortage issued to the short-term high electromagnetic relay, for watering potted plants temporarily, until the water fully spread again on the soil moisture sensor for processing incoming data in soil, repeat the above steps until the moisture content reaches the set value of the pot until.

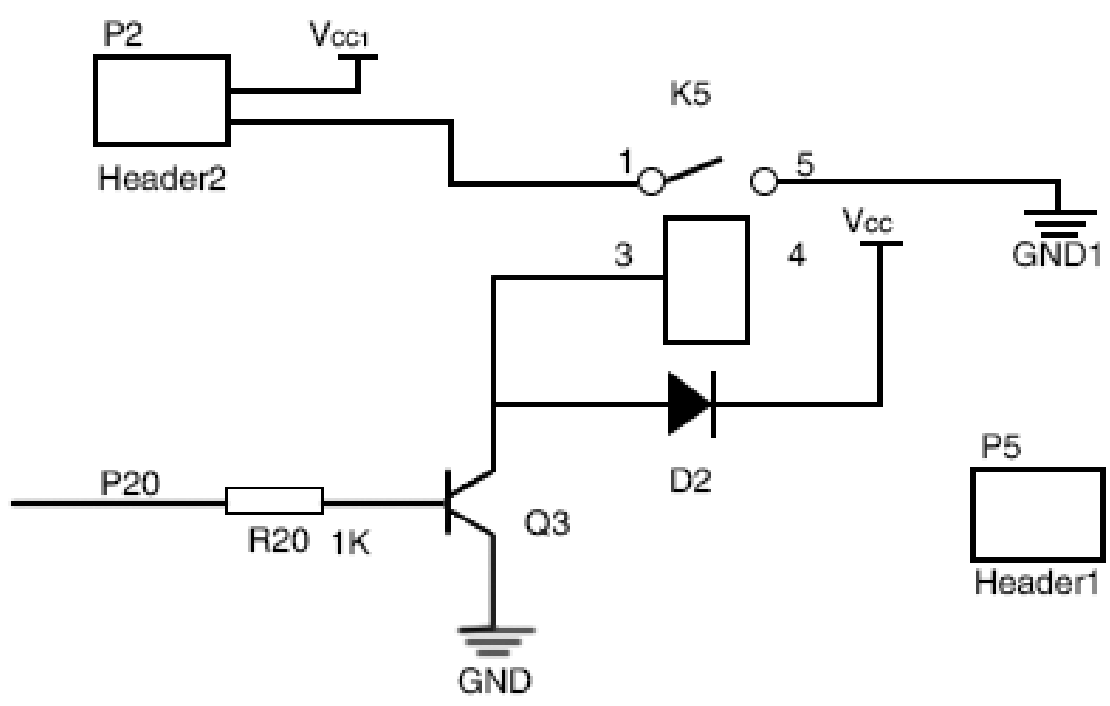

Fig. 3 The circuit of water pump

The action execution system based on the electromagnetic relay accepts the high level signal which is sent by the single chip microcomputer when the water shortage is short, the switch power supply is connected with the electromagnetic valve circuit, the electromagnetic valve is electrified, and the water in the water storage device is flowed out to the water in the pot [4]. 


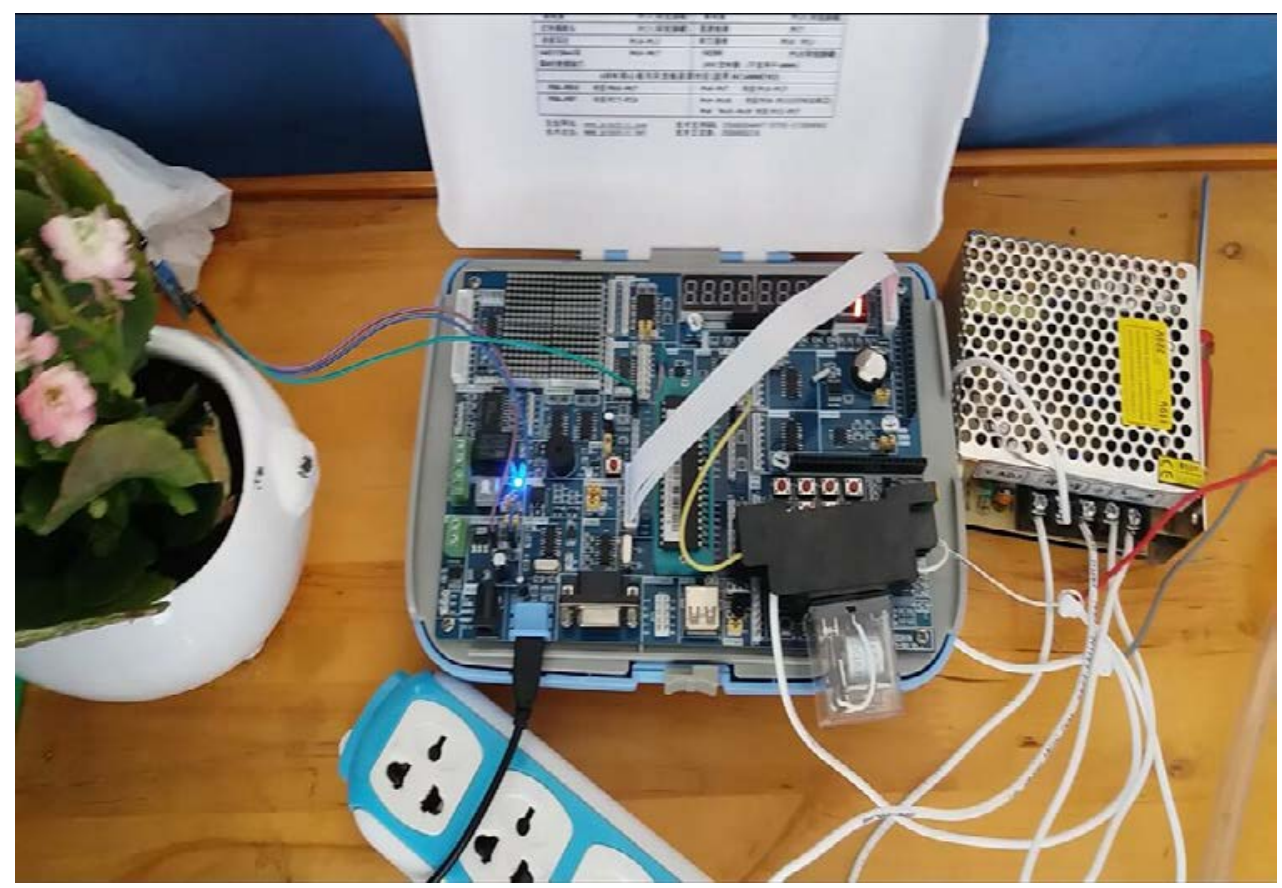

Fig. 4 The picture of Automatic watering potted microcontroller-based system

\section{Conclusions}

After the logical reasoning and theoretical calculation, we completed the production of the device. but we have encountered a lot of problems in the actual operation.

First, the electrical signal output by the microcontroller can not be directly identified by the electromagnetic relay, and the current is too small, cannot make the normal operation of the electromagnetic relay.

Second, China's voltage standard is $220 \mathrm{~V}$, but the solenoid valve cannot be under the normal operation of this voltage.

Third, a wide variety of plants, which increased the cost of virtually.

To solve these problems, we have adjusted and improved the whole system. If the microcontroller and the electromagnetic relay using the current amplifier; the use of power switches for the solenoid valve power supply; the introduction of the database to achieve a variety of functions of plant water.

Finally, the automatic watering system perfectly complete our initial vision!

\section{References}

[1]. Ming Chen, Xiaohui Xu, Tao song. The design of water-saving irrigation APP Based on the android platform [J]. Water-saving irrigation, 2013, 34( 9) : 82-89.

[2]. Information on: http://news.xinhuanet.com/science/2016-08/10/c_135581958.htm.

[3]. Information on: http://www.eepw.com.cn/article/279161.htm.

[4]. Chunming Wu, Xiaomin Mou, Liang Cheng. The research and design of Thermal power unit remote wireless monitoring system [J]. Automation instrument, 2013, 34( 6) : 42-44 